Article

\title{
Fabrication of Coatings with Structural Color on a Wood Surface
}

\author{
Yi Liu* ${ }^{\mathbb{D}}$, Jing $\mathrm{Hu}$ and Zhihui $\mathrm{Wu}$ * \\ College of Furnishings and Industrial Design, Nanjing Forestry University, Nanjing 210037, China; \\ hj_nanlin2019@126.com \\ * Correspondence: liuyi@njfu.edu.cn (Y.L.); wzh550@njfu.edu.cn (Z.W.); Tel.: +86-025-8542-7528 (Y.L.); \\ +86-025-8542-7793 (Z.W.)
}

Received: 19 November 2019; Accepted: 19 December 2019; Published: 1 January 2020

\begin{abstract}
A facile method for the fabrication of colloidal photonic crystal coatings with tunable structural color on a wood surface was presented. The photonic crystal coatings were formed from monodisperse latex spheres composed of poly(styrene-methyl methacrylate-acrylic acid) (P(St-MMA-AA)). The latex spheres with a hard PSt core and elastomeric P(MMA-AA) shell were prepared using the emulsion polymerization method. The sessile drop method, a rapid single-step self-assembly method through simple evaporation of emulsion, was used to form three-dimensional colloidal crystals. Coatings with brilliant colors and uniform Bragg's diffraction covering the entire visible region were fabricated by controlling the sphere size. This simple method provided new insight into the development of wood color embellishment.
\end{abstract}

Keywords: structural color; latex spheres; sessile drop method; wood; colloidal crystal

\section{Introduction}

Research shows that colors can easily be divided into two types: pigmentary colors and structural colors, depending on the origin of the colors. In the field of wood processing, the main strategy for coloring wood is by attaching dyes or pigments onto wood cells, which can be referred to as the pigmentation process. In outdoor applications, wood is usually colored by applying pigmented coatings and then painted for protection. The dyes for interior wood can be classified in the following common categories: direct dyes, basic dyes, acid dyes, and reactive dyes. The change of wood color is the result of dyes and pigments reforming the absorb and reflect wavelengths of visible light $[1,2]$. In the traditional coloring wood process, liquid waste containing pigments and dyes will cause water and soil pollution, and the colors easily fade away with time.

Structural colors present on the surface of periodic photonic crystals by the coherent diffraction of reflected light [3]. It is one of the distinguishing features of opals and inverse opal photonic crystals, which show high brightness, high saturation, and iridescence [4]. These materials have three-dimensional periodic structures and form the photonic band gaps (PBGs), where propagation of a certain range of electromagnetic wavelengths is forbidden [5]. The PBGs result from multiple scattering and Bragg's diffractions of light by the periodic photonic crystals [6]. Lots of colors can be observed by adjusting the structure of the photonic crystals and the viewing angle [7]. As structural color originates from interference, diffraction, or scattering of visible light in the periodic structures [8], it can be used to change the dyeing and mimic the beauty often observed in nature, such as on the surface of the scarab and the wings of morphos. Moreover, the coloration mechanism is relatively different from dyes and pigments.

Among the artificial constructive approaches, many researchers have focused on long-term, intensive strategies to synthesize monodisperse colloidal latex spheres for building photonic crystal 
structural colors. The photonic crystal can be constituted using the colloidal assembly method that has the characteristic of simplicity and easy-controllability [9]. Unlike most techniques, the colloidal self-assembly method provides a simple and efficient route for the synthesis of three-dimensional photonic crystals. Colloidal crystals can be prepared by the self-assembly of colloidal microspheres using several different techniques and fabrication strategies. Among the materials used for colloidal crystals, silica [10] and polymer [11] are the most common ones. The ordered lattice of air spheres in silica and polymer ordered structures predictably exhibits photonic band gap behavior.

Recently, the focus was on the application of photonic structural colors in the areas of inkless printing, reflective color displays, anti-counterfeiting materials, colorimetric sensors, gas sensors, paints, photonic papers, and cosmetics [12-15]. Nagayama et al. investigated different inter-particle forces that govern the packing of two-dimensional latex aggregates $[16,17]$. Xia et al. put forth an effective method for assembly by physical confinement [18]. Jiang et al. proposed a vertical deposition method to fabricate the photonic crystals [19]. However, it would require a long time for the preparation of large-scale samples.

Moreover, soaking for a long time would change the moisture content of wood and increase the likelihood of defects, like split and mildew attack [20-26]. Ríos-Osuna et al. employed several acrylates that have never been studied before as comonomers to be copolymerized with styrene. The chemical composition of the resulting spheres has been quantitatively contrasted to comonomers in the feed [27]. Yavuz et al. adopted the Disperse Red 343 dyestuff to dye latex spheres. The dyestuff can not only improve the monodispersity of microspheres but it also enhances the brightness and iridescent effect of the photonic crystals [28].

Poly(styrene-methyl methacrylate-acrylic acid) (P(St-MMA-AA)) latex spheres have been used widely to fabricate photonic crystal structure and extended colorful coatings [29]. With this background, this study aims to fabricate photonic crystal coatings with structural color onto a wood surface. The photonic crystal structures were obtained by the fabrication of monodisperse microspheres of P(St-MMA-AA) using a facile sessile drop process. Colloidal microspheres with perfect spherical shapes and controllable sizes to the submicrometer scale were prepared using the emulsion polymerization method. The photonic crystals with a face-centered cubic (fcc) structure on wood were obtained by self-assembly of the monodisperse P(St-MMA-AA) microspheres. The structural colors of the photonic crystals were brilliant, and the monochromatic colors on wood were obtained by controlling the diameters of the assembled latex microspheres. Variable color effects were also seen at different viewing angles.

\section{Materials and Methods}

\subsection{Materials and Substrates}

All reagents and chemicals were of reagent grade, and they were used without further purification. Styrene (St, $M_{\mathrm{w}}: 104.15 \mathrm{~g} / \mathrm{mol}$, CAS No.: 100-42-5), methyl methacrylate (MMA, $M_{\mathrm{w}}$ : 100.12g/mol, CAS No.: 80-62-6), acrylic acid (AA, $M_{\mathrm{w}}$ : 72.06g/mol, CAS No.: 79-10-7), sodium dodecyl benzene sulfonate (SDBS, $M_{\mathrm{W}}: 348.48 \mathrm{~g} / \mathrm{mol}$, CAS No.: 25155-30-0) were purchased from Shanghai Lingfeng Chemical Reagent Co., Ltd. (Shanghai, China). Ammonium persulfate (APS, $M_{\mathrm{w}}: 228.201 \mathrm{~g} / \mathrm{mol}$, CAS No.: 7727-54-0) was purchased from Nanjing Reagent Co., Ltd. (Nanjing, China). Ammonium bicarbonate $\left(M_{\mathrm{w}}: 79.06 \mathrm{~g} / \mathrm{mol}\right.$, CAS No.: 1066-33-7) was purchased from Sinopharm Chemical Reagent Co. Ltd. (Beijing, China). Distilled water was used in all the experiments. Poplar wood samples were bought from the local market and were sanded with abrasive paper (320\#), rinsed with distilled water, and then cut into the specimens with $2 \mathrm{~cm} \times 2 \mathrm{~cm} \times 2 \mathrm{~cm}$ (each sample) dimensions, before use.

\subsection{Synthesis of Monodisperse P(St-MMA-AA) Latex Spheres}

Monodisperse composite core-shell latex spheres of P(St-MMA-AA) were prepared according to a previously reported emulsion polymerization method, reported by Wang et al. [30]. St (19 g), MMA 
( $1 \mathrm{~g})$, AA ( $1 \mathrm{~g})$, distilled water (100 g), SDBS (0-0.02 g), and ammonium bicarbonate $(0.5 \mathrm{~g})$ were added sequentially to a three-necked, round-bottomed flask equipped with a reflux condenser, thermometer, and a mechanical stirrer at a stirring speed of $200 \mathrm{rpm}$. The reaction was carried out initially at $70{ }^{\circ} \mathrm{C}$ for $30 \mathrm{~min}$. The mixture turned to milky white by intensive mixing. Then the initiator APS was added to the reaction system. After the addition of an aqueous solution of APS ( $0.48 \mathrm{~g}$ dissolved in $15 \mathrm{~g}$ water), copolymerization was carried out for a further $6-10 \mathrm{~h}$ while stirring at $400 \mathrm{rpm}$. The copolymerization time was different for different SDBS contents. The resulting latex spheres were washed 3 times with water, centrifuged at 13,400 rpm, and ultrasonically dispersed, maintaining a concentration of $10 \mathrm{wt} . \%$.

\subsection{Fabrication of the Colloidal Crystal Coatings}

The sessile drop method was used to fabricate the photonic crystal coatings. The poplar wood samples used for the coatings were sanded with abrasive paper (320\#). Before being used for coating, the wood samples were rinsed with distilled water and then dried at $101^{\circ} \mathrm{C}$ in an oven to remove the water absorbed from the surface. The moisture content of the wood samples used for coating was about $10 \%$. The emulsions of monodisperse P(St-MMA-AA) latex spheres, synthesized using different amounts of SDBS, were dripped onto the surface of the wood. The concentration of the emulsions was $10 \mathrm{wt} . \%$. The emulsions were dispersed using the ultrasonic technique for $30 \mathrm{~min}$ before dripping. The coated woodblocks were dried at $50{ }^{\circ} \mathrm{C}$ in an air-dry oven until the coatings dried completely. To compare the visible light reflections of the coatings formed by different emulsion amounts per unit area, the dropping quantities of emulsion were set as $110,88,66,44$, and $22 \mu \mathrm{L} / \mathrm{cm}^{2}$.

\subsection{Characterization}

The intensity-average hydrodynamic sizes of the latex spheres in the emulsion were measured using dynamic light scattering (DLS) measurements with a particle size analyzer (Zetasizer Nano ZS, Malvern, UK). This technique measures the diffusion of spheres moving under Brownian motion and converts this to size and a size distribution using the Stokes-Einstein relationship. The instrument provided a constant temperature at $25{ }^{\circ} \mathrm{C}$ during the test. The dispersant of spheres for the test was water, and the concentration of the emulsion was a $1 \mathrm{wt} . \%$. The morphologies of the latex spheres were characterized by transmission electron microscopy (TEM, JEM1400 and JEM2100 UHR, JEOL, Tokyo, Japan). To determine the diameters of the monodisperse latex spheres in the TEM image, we measured the sizes of over 200 spheres using Image J software (versions 1.52a). In the sample preparation stage, the diluted emulsion was dripped onto the copper mesh and dried under the light. The copper mesh loaded with the spheres was fed into the test system by a sample rod. The TEM images were taken from multiple holes in a copper mesh. Scanning electron microscopic (SEM) images were obtained with a tabletop microscope (TM4000Plus, HITACHI, Tokyo, Japan). The wood samples with coatings adhered to the sample stage. After sputter coating with a thin layer of gold, the samples were placed in the sample storehouse. During the testing process, the sample chamber was guaranteed to have a certain degree of vacuum. Fourier transform infrared spectroscopic (FTIR) analysis was carried out using a Vertex 80V (Bruker, Bremen, Germany) to identify the functional groups present in the colloidal crystal coatings using ATR-FTIR. The wood samples were pressed closely with the ATR crystal. The infrared beam attenuated and reflected in the ATR crystal and reached the detector. The UV-Vis spectra were obtained using a UV-Vis spectrometer (Lambda 950, Perkin-Elmer, Waltham, MA, USA) with a $150 \mathrm{~mm}$ integrating sphere accessory. The background material used in the scan was barium sulfate. The wavelength range was set as 350 to $750 \mathrm{~nm}$. The infrared spectra and UV-Vis spectra of each type of coating were tested twice. The photographs of the woodblocks were recorded using a digital camera. The photos were acquired under natural light. 


\section{Results and Discussion}

\subsection{Monodisperse Core-Shell Latex Spheres}

Monodisperse latex spheres of P(St-MMA-AA) were prepared by single-step emulsion polymerization. The mechanism of nucleation of the latex spheres could be considered to be homogeneous nucleation [31-33]. A latex sphere with a hydrophobic polystyrene core and hydrophilic P(MMA-AA) shell was synthesized [34], as shown in Figure 1. The concentration of the emulsion for this image was $0.6 \%$. The polystyrene (dark part) was surrounded by P(MMA-AA) (light part). The spherical form showed the dependence of particle morphology on the MMA-AA/St ratio. The intensity-average hydrodynamic diameters of the spheres were 295.03, 289.66, 278.33, 278.15, and $258.96 \mathrm{~nm}$ when the SDBS in the emulsion polymerization system was $0,0.005,0.01,0.015 \mathrm{~g}$, and $0.02 \mathrm{~g}$. The measured diameters from the TEM results were 285, 254, 230, 223, and $193 \mathrm{~nm}$. These results illustrated that the diameters of spheres could be controlled by changing the amount of emulsifier in the polymerization system. The diameters measured with TEM were slightly smaller than the hydrodynamic diameters measured by DLS, similar to Tang et al. [11] and Ríos-Osuna et al. [27]. This phenomenon could be explained by the weak aggregation of the spheres and water loss shrinkage of the shell of spheres. In Figure 1, the diameter of the latex sphere was about $285 \mathrm{~nm}$ and the thickness of the shell part, formed from $\mathrm{P}(\mathrm{MMA}-\mathrm{AA})$ with abundant $\mathrm{COOH}$ groups, was about $45-50 \mathrm{~nm}$. The hydrophilicity of the co-monomer was the main parameter that influenced the morphology of the latex sphere. The outermost shell of the sphere was different from its core, wherein it was enriched with polar groups due to some degree of phase separation [35]. According to the literature, a significant decrease in the size of latex spheres after sample drying was observed when compared to the swollen and hydrated form in an aqueous medium. It was proposed that the change in size was primarily due to the evaporation of water from the PMMA and PAA rich peripheries of the spheres. Meanwhile, the spherical shape was effectively perceived to be the result of a dense PSt rich core.

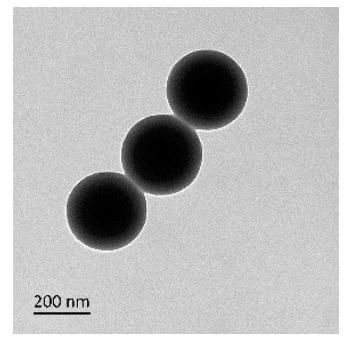

Figure 1. The transmission electron microscopy (TEM) image of core-shell latex spheres of $\mathrm{P}(\mathrm{St}-\mathrm{MMA}-\mathrm{AA})$ with diameters of about $285 \mathrm{~nm}$.

The TEM image (Figure 2) of the two-dimensional array formed from a 5\% emulsion of the sample suggested that there was an adhesive interaction at the inter-particle contact points. These latex spheres were aligned in two-dimensional long arrays on the copper mesh. The introduction of the soft monomer P(MMA-AA) increased the flexibility and facilitated the relaxation of the resulting polymer segments, owing to its high mobility. A more concentrated array of latex spheres demonstrated a marked difference in the spherical shape. These spheres dried and came into closer contact with each other. They spontaneously adopted this arrangement mode due to the uniform spherical shape and the flexibility and adhesiveness of soft interfaces of the shell. This adhesive between microspheres could be due to the network of the polymer during the evaporation of water. Figure 3 shows variations in the core and shell morphologies of spheres when more spheres were present, similar to McGrath et al. [35]. The shape became less spherical where the edges became conjoined as the spheres were forced together into a dense array, as shown by the red line. This result demonstrated the inter-particle adhesion between conjoint parts due to the hydrophilic PAA peripheries. Some spheres assembled in such a way that not only the shells but also the cores of the spheres were connected, as shown by 
the green line. Figure 3b,c shows the high resolution TEM image of the inter-particle contact points. This result also indicated a strong adhesive force between the latex spheres and contributed to the well-ordered arrangement of the latex spheres.

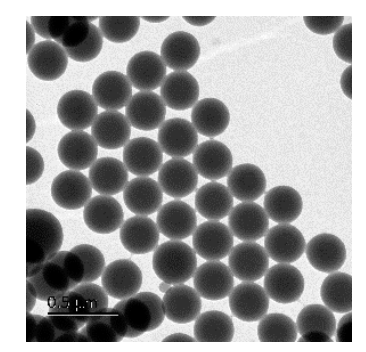

Figure 2. TEM image of a two-dimensional array formed from $5 \%$ emulsion.

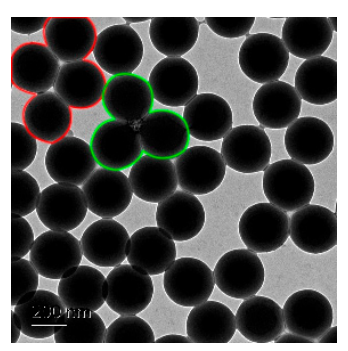

(a)

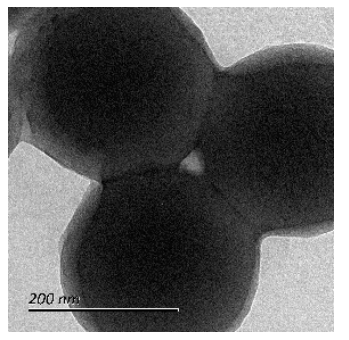

(b)

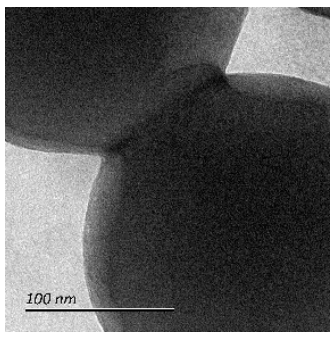

(c)

Figure 3. (a) TEM image showing variations in the morphologies of shells and cores for the higher concentration of spheres. $(\mathbf{b}, \mathbf{c})$ high-resolution TEM image of the inter-particle contact points.

\subsection{Fabrication of Colloidal Crystal Structure}

To obtain photonic crystals, we arranged the monodisperse core-shell latex spheres into a crystalline lattice. The sessile drop method was used for the coating of 3-D colloidal crystals onto the wood surface. The emulsion was coated on the surface of the wood substrate using a dropper. Since the raw wood was made of cells that possessed hierarchical microstructures [36], the main components of wood were cellulose, hemicellulose and lignin, which has many hydrophilic groups. The latex spheres self-assembled on the wood mainly through capillary force [16] and inter-particle forces when the water evaporated. The spheres filled the cell structure, then fabricated a well-ordered crystal structure. In this process, the soft shell-hard core morphology of latex spheres promoted the formation of a colloidal crystal, and the soft shell facilitated assembly of the latex spheres and the hard core enhanced crystalline stability [37].

Figure 4 presents a top-view SEM image of 3-D colloidal crystals on the wood surface, assembled by monodisperse latex spheres with diameters of about $230 \mathrm{~nm}$. It was evident that the majority of the microspheres formed a hexagonal structure and demonstrated long-range organized structures. The structure with cubic close-packed $\{111\}$ planes was oriented parallel to the substrate [38], with each sphere touching six others in one layer. As seen in Figure 5, the drying process in an air-dry oven resulted in the formation of cracks. The cracks are frequently observed in colloidal crystals fabricated with the rapid evaporation of the dispersant. The latex spheres shrunk during the assembly process. There was a difference in shrinkage between the wood and microspheres. Drying resulted in contraction that did not occur in the woodblocks. This could only be accompanied by the formation of cracks, which did not greatly impact the optical properties of the colloidal crystal structure. Figure 6 shows the cross-sectional SEM image of a 3-D colloidal crystal. The P(St-MMA-AA) spheres were arranged as typical $\{100\}$ facets of the fcc lattice. There was continuous air space between the arranged latex spheres, which demonstrated a typical feature of polymer-air bicontinuous fcc structures [39]. The 3-D uniformity of the colloidal crystals coating indicated the adhesion between latex spheres. 


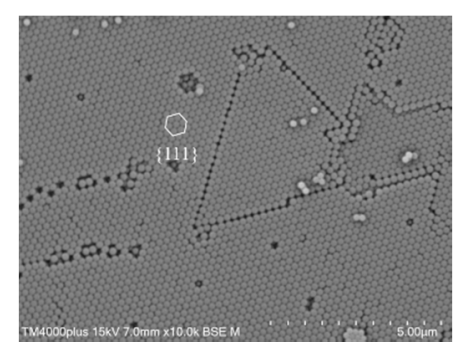

Figure 4. Scanning electron microscopic (SEM) image of P(St-MMA-AA) colloidal crystal coating assembled from spheres of $230 \mathrm{~nm}$ diameters.

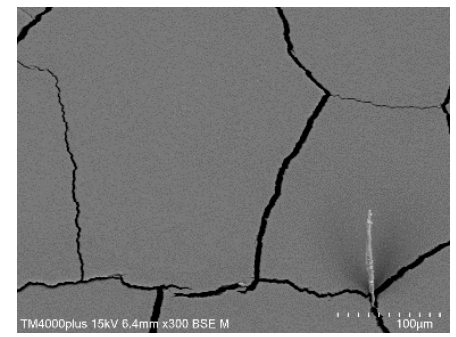

Figure 5. SEM image of microcracks formed during the drying of the coating.



Figure 6. Cross-sectional SEM image of the P(St-MMA-AA) colloidal crystal coating.

The order of colloidal crystal coatings may be due to the arrangement of the latex spheres by the interface and gravity joint self-assembly during dispersant evaporation. When the latex spheres assembled into a well-ordered crystal structure in the oven, there were three kinds of forces acting on the latex spheres. P(St-MMA-AA) latex spheres suspended in water before self-assembly, then a part of the spheres moved up to the air-liquid interface. The components of the spheres shell are PAA equipped with an abundant number of $\mathrm{COOH}$ groups and exhibited hydrophilicity which promoted the generation of hydrogen bonds. The hydrogen bonding interaction increased the bonding between the latex spheres and accelerated the process of self-assembly. Driven by capillary force and convection force, on the air-liquid interface, the initial colloidal crystals grow on the first layer.

Meanwhile, the hydrophilic P(MMA-AA) shell merged into a continuous matrix in an aqueous system. The shell part of the latex spheres assisted self-assembly of the particles in forming a close-packed ordered structure [35]. Then the latex spheres in the emulsion are assembled layer-by-layer to the first layer, which acts as a seed. At the same time, part of the sphere's sediment in the cell cavity of the wood surface under the action of gravity. The monodispersity of the spheres maintained the well-ordered arrangement during the fabrication of the photonic crystals [40]. Meanwhile, the hard and hydrophobic cores maintained the crystalline order structure [40,41]. These factors accelerated the arrangement of well-ordered latex spheres and contributed to the homogeneous colloidal photonic crystals on the wood surface.

The orderly structure of colloidal crystal coatings could be attributed to the elastomeric deformation of the P(MMA-AA) shell and the hydrogen bonding interactions between the carboxyl groups at the surface of the latex spheres. FTIR spectroscopic analysis helped to determine the functional groups and clarified the role of hydrogen bonds between the carboxyl groups on the shell of the latex spheres. 
The results are presented in Figure 7. The absorbance peak at $1729 \mathrm{~cm}^{-1}$ was ascribed to the hydrophilic $\mathrm{C}=\mathrm{O}$ groups of PAA, whereas the absorbance peaks at 1600,756 , and $701 \mathrm{~cm}^{-1}$ were ascribed to the hydrophobic benzene groups of PSt [8]. Absorption peaks in the spectra of all coatings at 3647, 3442, and $620 \mathrm{~cm}^{-1}$ could be ascribed to the vibrations of the $\mathrm{O}-\mathrm{H}$ groups. The peaks at around $3025 \mathrm{~cm}^{-1}$ were characteristic of $\mathrm{C}-\mathrm{H}$ in benzene. Peaks at around $2922 \mathrm{~cm}^{-1}$ corresponded to the $\mathrm{C}-\mathrm{H}$ stretching vibration absorption of $-\mathrm{CH}_{3}$ and $-\mathrm{CH}_{2-}$, and 1492 and $1450 \mathrm{~cm}^{-1}$ corresponded to the $\mathrm{C}-\mathrm{H}$ bending vibration peak in $-\mathrm{CH}_{2}-$. Thus, the formation of the core-shell morphology of the materials in the microspheres was confirmed by FTIR spectroscopy.

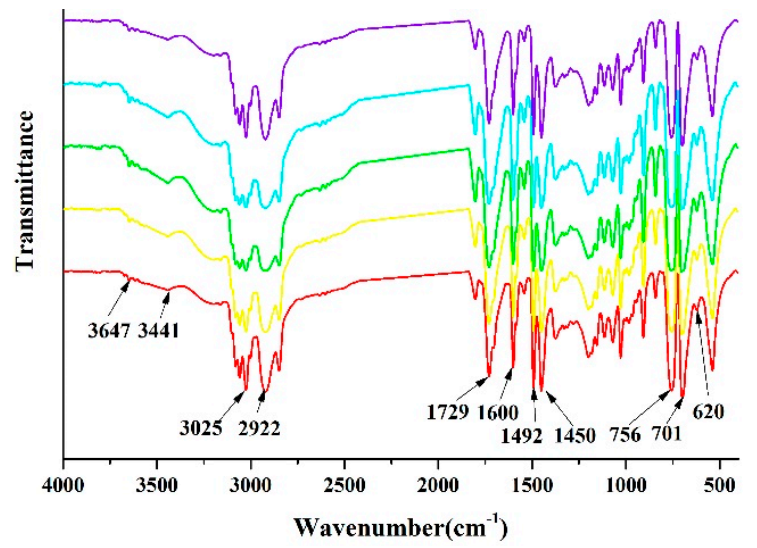

Figure 7. Fourier transform infrared spectroscopic (FTIR) spectroscopic analysis of colloidal crystal coatings prepared from spheres of different diameters.

\subsection{Full Color Colloidal Crystal Coatings}

When photonic crystals are used as surface finishing materials, the coatings exhibit brilliant colors [41,42] due to the stop bands laying in the visible region. In this work, red, yellow, green, cyan, and violet photonic crystal coatings were prepared on the wood surface using P(St-MMA-AA) latex spheres with diameters of 285, 254, 230, 223, and $193 \mathrm{~nm}$ measured using the TEM image, respectively. The color was consistent throughout the woodblock surface due to the well-ordered arrangement of spheres. The diameter modulation of the monodisperse latex spheres was variated by altering the ratio of emulsifier (SDBS) in the emulsion polymerization process. The emulsifier SDBS was distributed around the surface of the latex spheres, which ensured the formation of a stable emulsion system. Figure 8 shows a photograph of the coatings deposited on the wood surface. The amount of drop per square centimeter was $110 \mu \mathrm{L}$. The area of the coating was ca. $2 \times 2 \mathrm{~cm}^{2}$ and could be modulated with the size of the substrate. The brilliant structural colors of the coatings showed dependence on the viewing angle.
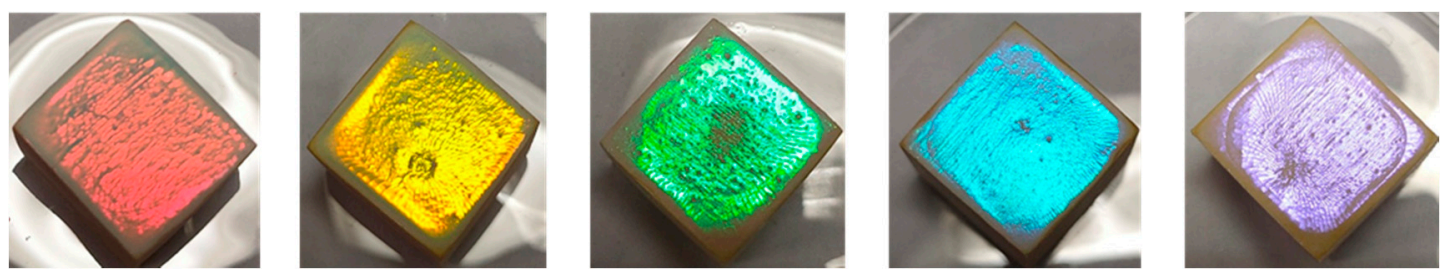

Figure 8. Images of the as-prepared coating deposited on the wood surface using spheres of different diameters.

The specific dimensions of latex spheres ensured that the stop band of the as-prepared photonic crystal coating covered the entire visible range. The colors resulted from the diffraction/reflectance of light from the colloidal photonic crystal as visualized by SEM (Figure 4). Relative reflectance spectroscopy was used to determine the wavelength of the Bragg's diffraction for the colloidal photonic 
crystal. The solid UV-Vis spectra could measure the surface of well-ordered photonic crystal and monochromatic structural colors in reflectance mode (along the crystallographic $\{111\}$ direction). As seen in Figure 9, a strong reflectance of coatings was observed. Peaks appeared at 621, 569, 514, 490, and $433 \mathrm{~nm}$. These wavelengths were consistent with the colors shown in Figure 8.

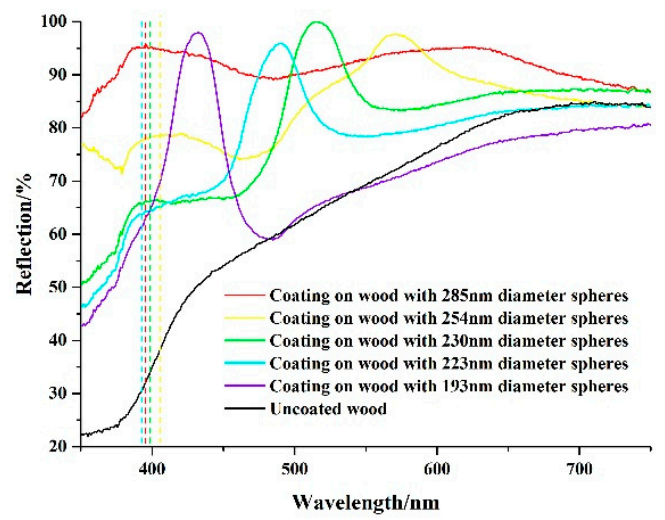

Figure 9. UV-Vis spectra of the coatings prepared using spheres of different diameters.

The spectra showed variations in the reflectance peaks with changes in the latex sphere sizes. Stop band positions were blue-shifted for spheres with smaller diameters packed with smaller lattice constants [43-45]. Thus, the sessile drop method was effective for the fabrication of the tunable photonic band gap and colloidal crystal structure on the wood surface. In the UV-Vis spectra of coatings composed of spheres of different diameters, the photonic crystals showed broad peaks and large backgrounds. This could be because the self-assembly of photonic crystals was influenced by the micron-scale tubular structures of the wood surface. The well-ordered structure was only present on the surface layer of the coatings. Colvin et al. reported that most of the radiations interacted only with a few lattice planes near the surface and there was no subsequent propagation through the photonic crystals [46]. Hence, the as-prepared photonic crystals demonstrated iridescent structural color (Figure 8).

In Figure 9, the curves of the red and yellow coatings showed a declining trend, whereas the curves of the green, cyan, and purple coatings showed an increasing trend in the wavelength range of $650 \mathrm{~nm}$ to $750 \mathrm{~nm}$. These trends were due to the influence of the wood base which showed an upward trend in the visible light range. The coatings, except the purple one, were assembled by spheres with diameters of $193 \mathrm{~nm}$ which were measured by the TEM image. They showed reflection peaks at wavelengths of 396 (red), 403 (yellow), 397 (green), and $391 \mathrm{~nm}$ (cyan). Figure 10 shows the diffuse reflectance spectra of the dried latex spheres, which showed peaks at 396 (red), 403 (yellow), 393 (green), and $391 \mathrm{~nm}$ (cyan). Thus, peaks at about $395 \mathrm{~nm}$ in the UV-Vis spectra of coatings on the wood surface were the result of diffuse reflectance of P(St-MMA-AA) microspheres.

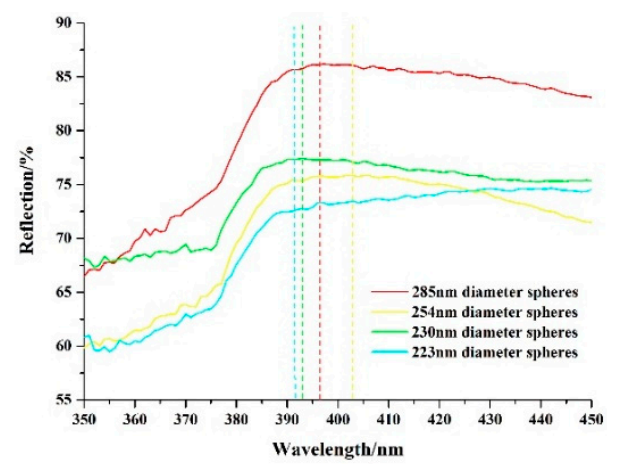

Figure 10. UV-Vis spectra of spheres of different diameters. 
We explained the influence of coating thickness on the structural color as the droplet quantity varied. Figure 11 shows the reflectance spectra of the coatings formed from the emulsions of different concentrations. The as-prepared photonic crystal coatings were formed from P(St-MMA-AA) latex spheres with diameters of $230 \mathrm{~nm}$. The number of spheres for self-assembly on the wood surface varied with the volume of an emulsion having the same concentration. Coatings with different thicknesses could be constructed on the same area of the wood substrate with different quantities of drops. In the image, the intensity of the reflection peaks decreased as the drop amount decreased. This phenomenon indicated that as the number of latex spheres increased, coating thickness and more effective crystal structures with a long-range ordering of latex spheres appeared. Figure 12 shows the images of coatings with different thicknesses. The coatings showed uniform structural color and excellent reflectivity. Coatings formed from more latex spheres completely shaded the wood surface and exhibited a more complete and bright color. It was worth noting that the reflection peaks red-shifted when the droplet amount increased from 66 to $88 \mu \mathrm{L} / \mathrm{cm}^{2}$. The reflection peaks appeared at wavelengths of $508 \mathrm{~nm}$ $\left(22,44\right.$ and $\left.66 \mu \mathrm{L} / \mathrm{cm}^{2}\right)$ and $514 \mathrm{~nm}\left(88\right.$ and $\left.110 \mu \mathrm{L} / \mathrm{cm}^{2}\right)$. This phenomenon could be attributed to the cellular structure of the wood surface. In Figure 12, the coatings formed from 22,44 and $66 \mu \mathrm{L} / \mathrm{cm}^{2}$ droplet amounts could still retain the texture of the wood cellular structure. When more drops were used to make coatings, the surface of coatings showed more distinct photonic crystal structures and cracks could be seen in the image.

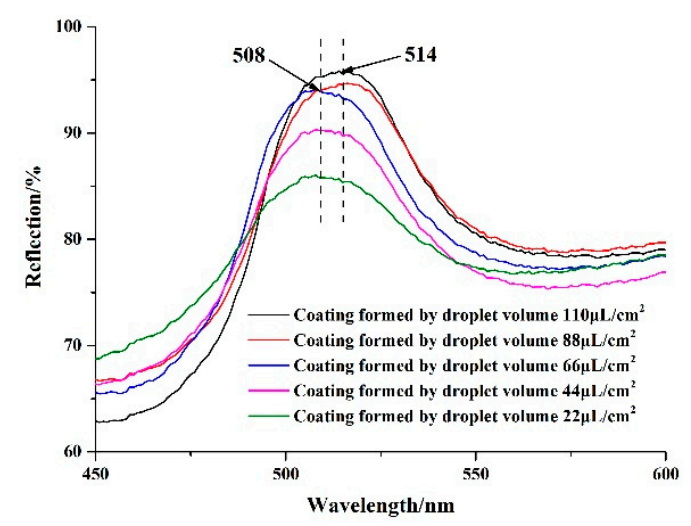

Figure 11. UV-Vis spectra of the coatings formed by different droplet amounts.
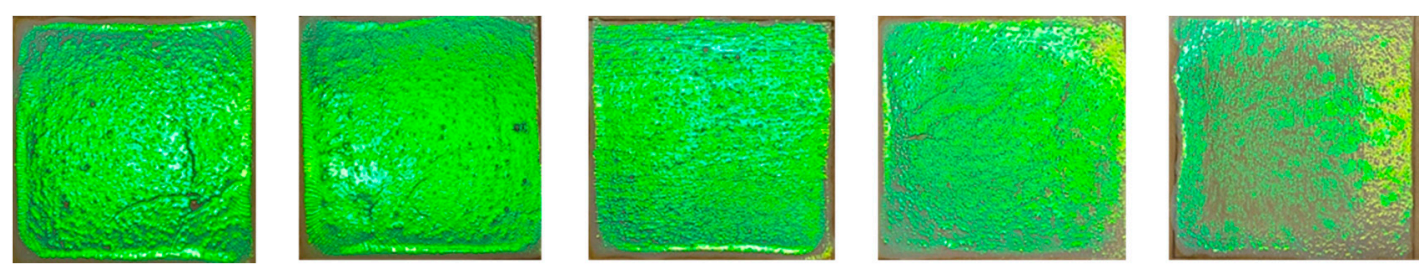

Figure 12. Photographs of the as-prepared coating deposited on the wood surface using $230 \mathrm{~nm}$ diameters latex spheres with different droplet amounts.

\section{Conclusions}

In conclusion, dried P(St-MMA-AA) colloidal crystal coatings were successfully fabricated on a wood surface using the sessile drop method. The colloidal crystal coatings were self-assembled from latex spheres with a core-shell structure using the emulsion evaporation method. Soft shells with an abundant number of $\mathrm{COOH}$ groups allowed for the ordering of spheres by introducing flexibility, whereas the hard core provided the final crystalline stability when fully dried. The dried coatings exhibited Bragg's diffraction and tunable brilliant and monochromatic structural colors covering the entire visible range. SEM and reflectance spectroscopy characterized the coatings and demonstrated the extent of the crystalline order. Variations in the number of latex spheres altered the integrity of the coating and optical properties. The results provided new insights into the coloring of a wood surface. 
Such a rapid fabrication of self-assembly of structural color coatings with tunable photonic band gaps on wood is of great significance for wood surface coating and improved performance.

Author Contributions: Y.L. and J.H. contributed to the synthesis, testing, data analysis, and wrote the manuscript. Z.W. provided constructive suggestions about this work. All authors have read and agreed to the published version of the manuscript.

Funding: This research was funded by the Scientific Research Foundation of Nanjing Forestry University (GXL 2018022).

Acknowledgments: The authors are grateful for financial support from the Scientific Research Foundation of Nanjing Forestry University (GXL2018022).

Conflicts of Interest: The authors declare no conflict of interest.

\section{References}

1. McPhedran, R.C.; Nicorovici, N.A.; McKenzie, D.R.; Rouse, G.W.; Botten, L.C.; Welch, V.; Parker, A.R.; Wohlgennant, M.; Vardeny, V. Structural colours through photonic crystals. Phys. B 2003, 338, $182-185$. [CrossRef]

2. Aguirre, C.I.; Reguera, E.; Stein, A. Colloidal photonic crystal pigments with low angle dependence. ACS Appl. Mater. Interfaces 2010, 11, 3257-3262. [CrossRef] [PubMed]

3. Yu, J.; Kan, C. Review on fabrication of structurally colored fibers by electrospinning. Fibers 2018, 4, 70. [CrossRef]

4. Matsushitaac, S.; Shimomura, M. Light-propagation patterns in freestanding two-dimensional colloidal crystals. Colloids Surf. A 2006, 284, 315-319. [CrossRef]

5. Yablonovitch, E. Inhibited Spontaneous Emission in Solid-State Physics and Electronics. Phys. Rev. Lett. 1987, 58, 2059-2062. [CrossRef]

6. Liau, L.C.K.; Huang, Y.K. Effects of influential factors on sedimentation self-assembly processing of photonic band gap crystals by relative humidity-controlled environments. Chem. Eng. Process. 2008, 47, 1578-1584. [CrossRef]

7. Zhou, L.; Liu, G.; Wu, Y.; Fan, Q.; Shao, J. The synthesis of core-shell monodisperse P(St-MAA) microspheres and fabrication of photonic crystals structure with tunable colors on polyester fabrics. Fibers Polym. 2014, 15, 1112-1122. [CrossRef]

8. Li, J.; Liang, G.; Zhu, X.; Yang, S. Exploiting nanoroughness on holographically patterned three-dimensional photonic crystals. Adv. Funct. Mater. 2012, 22, 2980-2986. [CrossRef]

9. Li, Q.; Zhang, Y.; Shi, L.; Qiu, H.; Zhang, S.; Qi, N.; Hu, J.; Yuan, W.; Zhang, X.; Zhang, K. Additive mixing and conformal coating of noniridescent structural colors with robust mechanical properties fabricated by atomization deposition. ACS Nano 2018, 12, 3095-3102. [CrossRef]

10. Wang, W.; Tang, B.; Ma, W.; Zhang, J.; Ju, B.; Zhang, S. Easy approach to assembling a biomimetic color film with tunable structural colors. J. Opt. Soc. Am. A 2015, 32, 1109-1117. [CrossRef]

11. Tang, B.; Zheng, X.; Lin, T.; Zhang, S. Hydrophobic structural color films with bright color and tunable stop-bands. Dyes Pigment 2014, 104, 146-150. [CrossRef]

12. Zhang, J.; Sun, Z.; Yang, B. Self-assembly of photonic crystals from polymer colloids. Curr. Opin. Colloid Interface Sci. 2009, 14, 103-114. [CrossRef]

13. Gu, Z.; Horie, R.; Kubo, S.; Yamada, Y.; Fujishima, A.; Sato, O. Fabrication of a metal-coated three-dimensionally ordered macroporous film and its application as a refractive index sensor. Angew. Chem. Int. Ed. 2002, 41, 1153-1156. [CrossRef]

14. Fenzl, C.; Hirsch, T.; Wolfbeis, O.S. Photonic Crystals for Chemical Sensing and Biosensing. Angew. Chem. Int. Ed. 2014, 53, 3318-3335. [CrossRef] [PubMed]

15. Moirangthem, M.; Arts, R.; Merkx, M.; Schenning, A.P. An Optical Sensor Based on a Photonic Polymer Film to Detect Calcium in Serum. Adv. Funct. Mater. 2016, 26, 1154-1160. [CrossRef]

16. Denknov, N.D.; Velev, O.D.; Kralchevsky, P.A.; Ivanov, I.B.; Yoshimura, H.; Nagayama, K. Two-dimensional crystallization. Nature 1993, 361, 26. [CrossRef] 
17. Denknov, N.D.; Velev, O.D.; Kralchevsky, P.A.; Ivanov, I.B.; Yoshimura, H.; Nagayama, K. Mechanism of formation of two-dimensional crystals from latex particles on substrates. Langmuir 1992, 8, 3183-3190. [CrossRef]

18. Park, S.H.; Xia, Y. Macroporous Membranes with Highly Ordered and Three-Dimensionally Interconnected Spherical Pores. Adv. Mater. 1998, 10, 1045-1048. [CrossRef]

19. Jiang, P.; Bertone, J.F.; Hwang, K.S.; Colvin, V.L. Single-Crystal Colloidal Multilayers of Controlled Thickness. Chem. Mater. 1999, 11, 2132-2140. [CrossRef]

20. Yan, X.; Qian, X.; Chang, Y. Preparation and Characterization of Urea Formaldehyde @ Epoxy Resin Microcapsule on Waterborne Wood Coatings. Coatings 2019, 9, 475. [CrossRef]

21. Yan, X.; Wang, L.; Qian, X. Effect of High-Temperature Calcined Wheat Straw Powder after Lignin Removal on Properties of Waterborne Wood Coatings. Coatings 2019, 9, 444. [CrossRef]

22. Yan, X.; Wang, L.; Qian, X. Effect of Urea-Formaldehyde-Coated Epoxy Microcapsule Modification on Gloss, Toughness and Chromatic Distortion of Acrylic Copolymers Waterborne Coating. Coatings 2019, 9, 239. [CrossRef]

23. Wu, Y.; Sun, Y.; Yang, F.; Zhang, H.; Wang, Y. The implication of Benzene-Ethanol extractive on mechanical properties of waterborne coating and wood cell wall by nanoindentation. Coatings 2019, 7, 449. [CrossRef]

24. Wu, Y.; Wu, J.; Wang, S.; Feng, X.; Chen, H.; Tang, Q.; Zhang, H. Measurement of mechanical properties of multilayer waterborne coatings on wood by nanoindentation. Holzforschung 2019, 9, 1-7. [CrossRef]

25. Zhao, Z.; Sakai, S.; Wu, D.; Chen, Z.; Zhu, N.; Huang, C.; Sun, S.; Zhang, M.; Umemura, K.; Yong, Q. Further exploration of sucrose-citric acid adhesive: Investigation of optimal hot-pressing conditions for plywood and curing behavior. Polymers 2019, 11, 1996. [CrossRef]

26. Zhao, Z.; Sun, S.; Wu, D.; Zhang, M.; Huang, C.; Umemura, K.; Yong, Q. Synthesis and characterization of sucrose and ammonium dihydrogen phosphate (SADP) adhesive for plywood. Polymers 2019, 11, 1909. [CrossRef]

27. Ríos-Osuna, L.A.; Licea-Claverie, A.; Paraguay-Delgado, F.; Cortez-Lemus, N.A. Synthesis of poly (styrene-acrylates-acrylic acid) microspheres and their chemical composition towards colloidal crystal films. Int. J. Polym. Sci. 2016, 2, 1-10. [CrossRef]

28. Yavuz, G.; Felgueiras, H.P.; Ribeiro, A.I.; Seventekin, N.; Zille, A.; Souto, A.P. Dyed poly (styrene-methyl methacrylate-acrylic acid) photonic nanocrystals for enhanced structural color. ACS Appl. Mater. Interfaces 2018, 10, 23285-23294. [CrossRef]

29. Müller, M.; Zentel, R.; Maka, T.; Romanov, S.G.; Sotomayor-Torres, C.M. Photonic Crystal Films with High Refractive Index Contrast. Adv. Mater. 2000, 12, 1499-1503. [CrossRef]

30. Wang, J.; Wen, Y.; Feng, X.; Song, Y.; Jang, L. Control over the wettability of colloidal crystal films by assembly temperature. Macromol. Rapid Commun. 2006, 27, 188-192. [CrossRef]

31. Chen, S.; Chang, H.; Feng, X.; Song, Y.; Jang, L. Kinetics and mechanism of emulsifier-free emulsion polymerization: Styrene/surface active ionic comonomer system. J. Polym. Sci. Polym. Chem. Ed. 1985, 23, 2615-2630. [CrossRef]

32. Hansen, F.K.; Ugelstad, J.; Feng, X.; Song, Y.; Jang, L. Particle nucleation in emulsion polymerization. I. A theory for homogeneous nucleation. J. Polym. Sci. Polym. Chem. Ed. 1978, 16, 1953-1979. [CrossRef]

33. Feeney, P.J.; Napper, D.H.; Gilber, R.G. Surfactant-free emulsion polymerizations: Predictions of the coagulative nucleation theory. Macromolecules 1987, 20, 2922-2930. [CrossRef]

34. Wang, J.; Wen, Y.; Feng, X.; Hu, J.; Song, Y.; Jang, L. Fine control of the wettability transition temperature of colloidal crystal films: From superhydrophilic to superhydrophobic. Adv. Funct. Mater. 2007, 17, $219-225$. [CrossRef]

35. McGrath, J.G.; Bock, R.D.; Cathcart, J.M.; Lyon, L.A. Self-assembly of "paint-on" colloidal crystals using poly (styrene-co-N-isopropylacrylamide) spheres. Chem. Mater. 2007, 19, 1584-1591. [CrossRef]

36. Plötze, M.; Niemz, P. Porosity and pore size distribution of different wood types as determined by mercury intrusion porosimetry. Eur. J. Wood Wood Prod. 2011, 69, 649-657. [CrossRef]

37. Kalinina, O.; Kumacheva, E. A "core-shell" approach to producing 3D polymer nanocomposites. Macromolecules 1999, 32, 4122-4129. [CrossRef]

38. Míguez, H.; Meseguer, F.; López, C.; Mifsud, A.; Moya, J.S.; Vázquez, L. Evidence of FCC Crystallization of $\mathrm{SiO}_{2}$ Nanospheres. Langmuir 1997, 13, 6009-6011. [CrossRef]

39. Texter, J. Polymer colloids in photonic materials. C. R. Chim. 2003, 6, 1425-1433. [CrossRef] 
40. Park, S.H.; Xia, Y. Assembly of mesoscale particles over large areas and its application in fabricating tunable optical filters. Langmuir 1999, 15, 266-273. [CrossRef]

41. Ruhl, T.; Hellmann, G.P. Colloidal Crystals in Latex Films: Rubbery Opals. Macromol. Chem. Phys. 2001, 202, 3502-3505. [CrossRef]

42. Ruhl, T.; Spahn, P.; Hellmann, G.P. Artificial opals prepared by melt compression. Polymer 2003, 44, 7625-7634. [CrossRef]

43. Subramania, G.; Constant, K.; Biswas, R.; Sigalas, M.M.; Ho, K.-M. Optical photonic crystals fabricated from colloidal systems. Appl. Phys. Lett. 1999, 74, 3933-3935. [CrossRef]

44. Subramania, G.; Constant, K.; Biswas, R.; Sigalas, M.M.; Ho, K.-M. Inverse Face-Centered Cubic Thin Film Photonic Crystals. Adv. Mater. 2001, 13, 443-446. [CrossRef]

45. Schroden, R.C.; Al-Daous, M.; Stein, A. Self-Modification of Spontaneous Emission by Inverse Opal Silica Photonic Crystals. Chem. Mater. 2001, 13, 2945-2950. [CrossRef]

46. López, C. Materials Aspects of Photonic Crystals. Adv. Mater. 2003, 15, 1679-1704. [CrossRef]

(C) 2020 by the authors. Licensee MDPI, Basel, Switzerland. This article is an open access article distributed under the terms and conditions of the Creative Commons Attribution (CC BY) license (http://creativecommons.org/licenses/by/4.0/). 